Al-Azhar Bull. Sci. Vol. 19, No. 1 (June.): pp. 135-151, 2008.

\title{
EFFECT OF TWO TRIAZOLE THIONE DERIVATIVES ON CORROSION BEHAVIOR OF MOLYBDENUM IN O.01M HCL
}

\author{
E. M. ATTIA
}

Chemistry Department, Faculty of Science (for Girls), AL-Azhar University, Cairo, Egypt.

\begin{abstract}
$4 \mathrm{~N}$ - (2- hydroxy -3- triethyl ammonio- propyl-) fatty- 1, 2, 4 triazole -3- thione (12AB) and 2,4N- (bis- 2- hydroxy -3- triethyl ammonio- propyl-) fatty- 1, 2, 4 triazole -3- thione $(12 \mathrm{ABB})$ were synthesized, characterized and tested as surfactant corrosion inhibitors for Mo in $0.01 \mathrm{M} \mathrm{HCl}$ solution using galvanostatic, potentiodynamic and potentiostatic polarization techniques. Concentrations of the inhibitors were ranged from $1 \times 10^{-6}$ to 1 (wt. \%). The obtained results using galvanostatic polarization on bare metal showed that thickness of adsorbed layer decreased with increasing concentration of $12 \mathrm{AB}$ while adverse trend was observed with $12 \mathrm{ABB}$. On the other hand the anodic oxide film formed at $100 \mathrm{mAcm}^{-2}$ up to $0.268 \mathrm{~V}$ (SCE) was susceptible to a dissolution process with the presence of two corrosion rates for each concentration of the two additives. Potentiodynamic polarization illustrated that increase of additive concentration lowered corrosion current densities affecting anodic reaction more than cathodic one. The protection efficiency increased with increasing inhibitor concentration. The low values of IE. \% indicated the presence of electrostatic attraction between inhibiting molecules and the electrically charged surface of metal. Adsorption followed the kinetic thermodynamic model, Langmuir and Flory-Huggins adsorption isotherms. $12 \mathrm{ABB}$ showed better inhibiting action than that of $12 \mathrm{AB}$ due to the presence of two side chains in its structure. Potentiostatic polarizations indicated that when the concentration of the additives $12 \mathrm{AB}$ and $12 \mathrm{ABB}$ exceeded a critical value, $\geq 0.1 \mathrm{Wt} . \%$, no inhibition effect.
\end{abstract}

Key words: triazole thione, corrosion, molybdenum, galvanostatic, potentiodynamic, potentiostatic, polarization, adsorption.

\section{Introduction}

The corrosion of metallic materials in acidic solutions causes considerable costs. The use of inhibitors are one of the most practical methods for protection against corrosion in acidic media ${ }^{(1,2)}$. Most commercial acid inhibitors are surfactant compounds containing nitrogen, sulphur, and/ or oxygen atoms ${ }^{(3-7)}$. The adsorption of a surfactant markedly changes the corrosion resisting property of a metal, and for these reasons, studies of the relation between adsorption and corrosion inhibition are of considerable importance ${ }^{(8-11)}$. The relationship between the adsorption of surfactants and their molecular structures has attracted the attention of many investigators ${ }^{(12-15)}$. As a representative type of surfactant inhibitors, derivatives of quaternary ammonium salts have been demonstrated and used widely in various industrial processing for preventing corrosion in acidic media (16-19). Cationic surfactants are classified as very good inhibitors ${ }^{(20-25)} .12 \mathrm{AB}$ [4N- (2-hydroxy-3- 
triethyl ammonio- propyl-) fatty- 1, 2, 4 triazole - 3 - thione ] and $12 \mathrm{ABB}[(2,4 \mathrm{~N}$ - (bis2- hydroxy -3- triethyl ammonio- propyl-) fatty- 1, 2, 4 triazole -3- thione )] are kinds of new cationic surfactants which tested as corrosion inhibitor compounds.

Several different electrochemical techniques were used to study the redox reaction in an aqueous acid solution at molybdenum oxide film electrode ${ }^{(26-30)}$. In $\mathrm{H}_{2} \mathrm{SO}_{4}$ and acidic sulphate solutions, steady state polarization curves exhibit a twoTafel slope suggesting the concurrence of two parallel reaction paths ${ }^{(31,32)}$. The oxide film formed in $\mathrm{H}_{2} \mathrm{SO}_{4}, \mathrm{H}_{3} \mathrm{PO}_{4}, \mathrm{HCl}$ and $\mathrm{Na}_{2} \mathrm{SO}_{4}$ is highly stable and the stability was attributed to its compact and non-defective structure ${ }^{(28)}$. Also, the passive films undergo structural changes during the course of measurements which may be attributed to a further oxidation of the passive $\mathrm{MoO}_{2}$ film to $\mathrm{MoO}_{3}{ }^{(29)}$. The aim of this work is to study the effect of $12 \mathrm{AB}$ and $12 \mathrm{ABB}$ on the corrosion of molybdenum in $0.01 \mathrm{M} \mathrm{HCl}$ solution with different polarization methods. Also, investigate the adsorption mechanism of these inhibitors on Mo surface.

\section{Experiment}

The $0.01 \mathrm{M}$ hydrochloric acid solution was prepared using reagent grade concentrated acid and bi-distilled water. The tested inhibitors, namely, 4N- (2hydroxy -3- triethyl ammonio- propyl-) fatty- 1, 2, 4 triazole -3- thione (12AB) and 2,4N- (bis- 2- hydroxy -3- triethyl ammonio- propyl-) fatty- 1, 2, 4 triazole -3thione $(12 \mathrm{ABB})$ were dissolved in $0.01 \mathrm{M} \mathrm{HCl}$ at various concentrations $\left(1 \times 10^{-6}\right.$ to 1 wt. $\%)$. The molecular structures of $12 \mathrm{AB}$ and $12 \mathrm{ABB}$ are:<smiles>[R]c1n[nH]c(=S)n1[B]</smiles><smiles>[R]c1n[n-]c(=S)n1[B]</smiles>

$$
\begin{aligned}
& \mathrm{R}=\mathrm{CH}_{3}\left(\mathrm{CH}_{2}\right)_{11}, \\
& \mathrm{~B}=\mathrm{CH}_{2} \mathrm{CHOH} \mathrm{CH}_{2} \mathrm{~N}\left(\mathrm{C}_{2} \mathrm{H}_{5}\right)_{3} \mathrm{OH}^{-}
\end{aligned}
$$

The specimen is made of massive cylindrical and spectroscopically pure molybdenum rod (Aldrich-Chemie). A stout copper wire was employed as electrical contact. The surface preparation of the specimen was carried out using emery paper up to grade 1200. After polishing, the specimen was washed with distilled water, degreased with acetone and rinsed with bi-distilled water. Then the electrode was fitted into glass tubing of appropriate internal diameter with epoxy resin leaving a circular surface area of $0.196 \mathrm{~cm}^{2}$ to contact the electrolyte.

Electrochemical experiments were carried out in a double- walled glass cell. Platinum sheet $\left(4 \mathrm{~cm}^{2}\right)$ was used as a counter while saturated calomel electrode 
(SCE) provided with a Luggin capillary probe was used as a reference electrode. The corrosion cell was filled with a known amount $(50 \mathrm{ml})$ of test solution.

Galvanostatic polarization measurements were made in $0.01 \mathrm{M} \mathrm{HCl}$ solution at various constant current densities: 10, 30, 50, 100, 200, 500 and $1000 \mu \mathrm{Acm}^{-2}$. The potentials were measured against a saturated calomel electrode with the aid of digital multimeter (KEITHLEY, model 175, USA). Potentiostatic measurements were performed at the following potentials with respect to SCE: 100, 200, 300, 400, 500, 600 and $900 \mathrm{mV}$ (SCE). In potentiodynamic technique the anodic E/I curves for all solutions were swept from $-2 \mathrm{~V}(\mathrm{SCE})$ to $3 \mathrm{~V}(\mathrm{SCE})$ at scan rate of $6.7 \mathrm{mV} / \mathrm{s}$. Potentiostatic and potentiodynamic polarization measurements were generated using a Wenking Electronic Potentioscan (model 73). All measurements were carried out at room temperature $\left(30^{\circ} \mathrm{C}\right)$.

\section{Results and Discussion}

\section{Galvanostatic polarization measurements:}

Behavior of bare molybdenum electrode in $0.01 \mathrm{M} \mathrm{HCl}$

The potential- time polarizing curves are illustrated in Figure (1). At very small current densities $\left(10\right.$ and $\left.30 \mu \mathrm{Acm}^{-2}\right)$ the potentials were found to increase with time towards more positive values. This passivation is due to the presence of $\mathrm{Mo}_{2} \mathrm{O}_{5}$ layers which formed in the presence of chloride ions ${ }^{(33)}$. At moderate current densities $\left(50,100\right.$ and $\left.200 \mu \mathrm{Acm}^{-2}\right)$ the metal first passivated then dissolved with small rate. At 500 and $1000 \mu \mathrm{Acm}^{-2}$ the potentials were firstly increased in the first 15 and 5 second respectively, and then started to decrease. These small periods of time were invisible in the diagram. At these high current densities the metal is susceptible to dissolution and electropolishing rather than passivation; the soluble product may be molybdate or molybdic acid ${ }^{(30,28)}$.

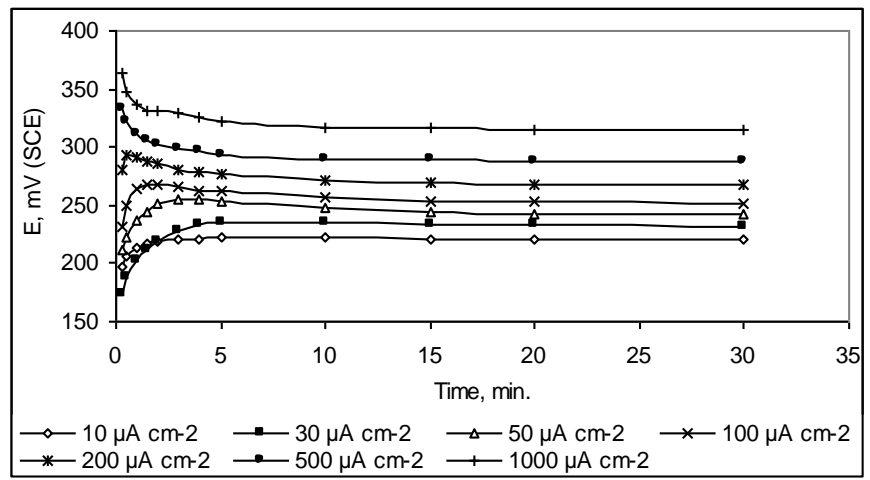

Figure (1): Anodic polarization curves for molybdenum electrode in $0.01 \mathrm{M} \mathrm{HCl}$ at different current densities 
On the other hand at $50 \mu \mathrm{Acm}^{-2}$, the presence of compounds $12 \mathrm{AB}$ and $12 \mathrm{ABB}$ in different weight percentages soluble in $0.01 \mathrm{M} \mathrm{HCl}$ solution shifted the stabilized potential to more positive values (Figure 2, a and $b$ ). This might be attributed to the adsorption of compounds $12 \mathrm{AB}$ and $12 \mathrm{ABB}$ to the oxide surface on Mo. This adsorption depends mainly on the charge and nature of the metal surface, electronic characteristic of the molecules $12 \mathrm{AB}$ and $12 \mathrm{ABB}$ and on the electrochemical potential at solution interface ${ }^{(34)}$. The ability of the chloride ions present in solution to penetrate and dissolve the oxide layer was diminished at this current density. An interpretation of the influence of chloride ions on anodic behavior has been put forward using solid state concepts. It was found that $\mathrm{Cl}^{-}$did not affect passivation rate of molybdenum. This could be explained by the high metal- metal bond energies of Mo and also the high lattice energies of its oxides, which made it more difficult for metal ions to leave the lattice of the corresponding metal oxide ${ }^{(37)}$.

The characteristic polarization data for Mo in absence and presence of the two additives (12AB and $12 \mathrm{ABB})$ revealed that for all concentrations of additives, the time required for attaining stabilization was concentration dependent (Figure 2). The increase of potential with time was associated with film thickening due to adsorption which is below the limit necessary to attack the oxide and thus adsorbed oxide growth is favored to reach the steady state ${ }^{(36)}$.

The reciprocal capacitance $\left(\mathrm{C}^{-1}\right)$, was in proportion to the thickness of the oxide film ${ }^{(37,38)}$ where: $\mathrm{d}=\varepsilon \varepsilon^{\circ} \mathrm{C}^{-1}$

Where $\mathrm{d}$, is the thickness of the oxide film, $\varepsilon$, is the dielectric constant of oxide and $\varepsilon^{\circ}$, is the permittivity of free space $\left(8.85 \times 10^{-14} \mathrm{Fcm}^{-1}\right)$. By increasing concentrations of additives, the values of $\mathrm{C}^{-1}$ and consequently thickness of adsorbed layer decreased for $12 \mathrm{AB}$ and increased for $12 \mathrm{ABB}$ (Table1).
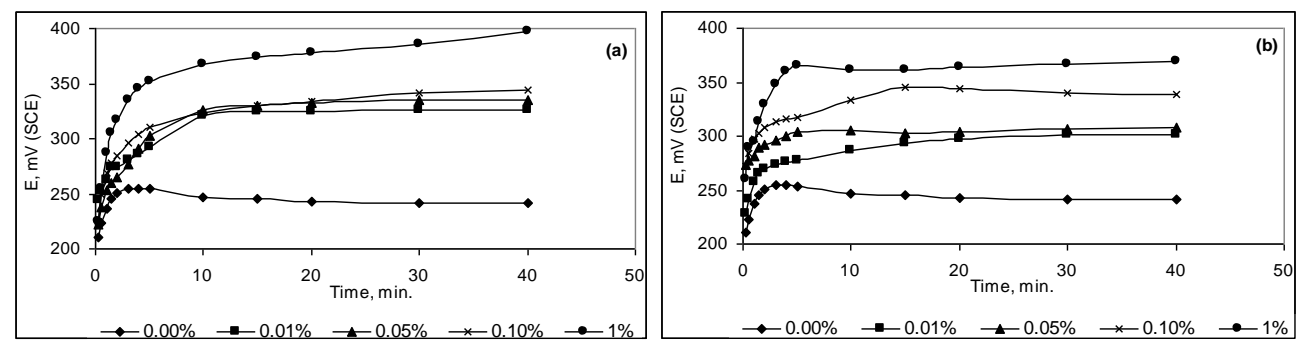

Figure (2): $\mathrm{Mo}$ in $0.01 \mathrm{M} \mathrm{HCl}$ containing different concentrations of Additives at $50 \mu \mathrm{A} \mathrm{cm}^{-2}$ : (a) in presence of $12 \mathrm{AB}$ and (b) in presence of $12 \mathrm{ABB}$ 
Table (1): Characteristic polarization data of Mo electrode in $0.01 \mathrm{M} \mathrm{HCl}$ containing different weight percentages of additives $12 \mathrm{AB}$ and $12 \mathrm{ABB}$ at $50 \mu \mathrm{Acm}^{-2}$

\begin{tabular}{|c|c|c|c|c|c|}
\hline Additive & $\begin{array}{l}\text { Wt.\% in } \\
0.01 M \text { HCl }\end{array}$ & $\begin{array}{c}\mathbf{E}_{\mathrm{ss}} \\
\mathbf{V}\end{array}$ & $\begin{array}{l}\mathrm{Q \times 10^{4 }} \\
\mu \mathrm{Ccm}^{-2}\end{array}$ & $\begin{array}{l}\mathrm{C} \times 10^{4} \\
\mu \mathrm{Fcm}^{-2}\end{array}$ & $\begin{array}{l}\mathrm{C}^{-1} \times 10^{-6} \\
\mu \mathrm{F}^{-1} \mathrm{~cm}^{2}\end{array}$ \\
\hline $\begin{array}{c}\text { Blank } \\
0.01 \mathrm{M} \mathrm{HCl}\end{array}$ & 0.00 & 0.240 & 6.0 & 25.000 & 4.00 \\
\hline \multirow{5}{*}{$(12 \mathrm{AB})$} & 0.01 & 0.326 & 3.6 & 11.042 & 9.05 \\
\hline & 0.05 & 0.335 & 3.9 & 11.642 & 8.58 \\
\hline & 0.10 & 0.344 & 4.5 & 13.081 & 7.64 \\
\hline & 0.40 & 0.369 & 9.0 & 24.390 & 4.10 \\
\hline & 1.00 & 0.397 & 9.0 & 22.670 & 4.41 \\
\hline \multirow{5}{*}{$(12 \mathrm{ABB})$} & 0.01 & 0.302 & 6.0 & 19.867 & 5.03 \\
\hline & 0.05 & 0.308 & 4.5 & 14.610 & 6.84 \\
\hline & 0.10 & 0.339 & 4.8 & 14.159 & 7.06 \\
\hline & 0.40 & 0.349 & 4.5 & 12.893 & 7.75 \\
\hline & 1.00 & 0.369 & 3.9 & 10.569 & 9.46 \\
\hline
\end{tabular}

The inflection of the line between $\mathrm{C}^{-1}$ and concentration indicated that the nature of oxide film thickening on molybdenum in $0.01 \mathrm{M} \mathrm{HCl}$ containing $12 \mathrm{ABB}$ changed after certain concentration $(0.05 \mathrm{Wt} . \%)$. In $0.01 \mathrm{M} \mathrm{HCl}$ containing $12 \mathrm{AB}$, the decrease in $\mathrm{C}^{-1}$ correlated with concentration indicated the instability of the layer (Figure 3).

At extremely low concentration of $12 \mathrm{ABB}$, the adsorption might take place by horizontal binding. This is favored by an electrostatic interaction between the nitrogen atoms in triazole thione ring as well as the two nitrogen atoms from the side chains and negatively charged metal surface in acid medium. As the concentration increases, a perpendicular adsorption may takes place beside the horizontal adsorption till saturating all active sites ${ }^{(22)}$. In case of $12 \mathrm{AB}$, molecules were adsorbed onto the metal surface through the nitrogen atoms of the ring and that of the side chain. At higher concentrations, stronger interactions may result in desorption of one or more adsorbed layer from the metal surface ${ }^{(22)}$.

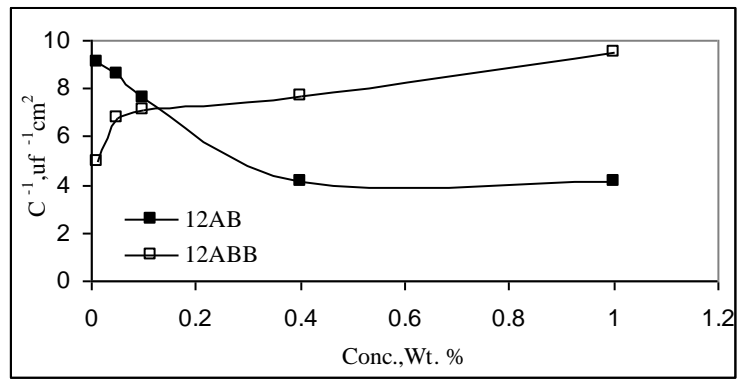

Figure (3): Variation of $\mathrm{C}^{-1}$ with wt. $\%$ of additives $12 \mathrm{AB}$ and 12ABB soluble in $0.01 \mathrm{M} \mathrm{HCl}$ for $\mathrm{Mo}$ electrode at $50 \mu \mathrm{Acm}^{-2}$ 
Plotting $\mathrm{E}_{\mathrm{ss}}$ versus log concentration of inhibitor for additives $12 \mathrm{AB}$ and $12 \mathrm{ABB}$ showed a linear relation (Figure 4) which could be represented as:

$$
\mathrm{E}_{\mathrm{ss}}=\alpha+\beta \log \mathrm{C}_{\text {inh. }}
$$

Where $\alpha$, is a constant depending on the nature of solution, $\beta$, is the slope of the linear relation. The values of $\beta$ are 33 and $50 \mathrm{mV} / \log \mathrm{C}$ for additives $12 \mathrm{AB}$ and $12 \mathrm{ABB}$ respectively. The values of $\beta$ were not so far from zero potential compared with the behavior of titanium in different bromide solutions in which the slope values were 427, 75 and $223 \mathrm{mV} / \log \mathrm{C}$ in $\mathrm{HBr}, \mathrm{NaBr}$ and $\mathrm{MgBr}_{2}$ respectively ${ }^{(39)}$. This indicates the moderate concentration effect of additives on the corrosion inhibition of $\mathrm{Mo}$ in $0.01 \mathrm{M} \mathrm{HCl}$ solution. The inhibition effect of $12 \mathrm{ABB}$ is stronger than that of $12 \mathrm{AB}$.

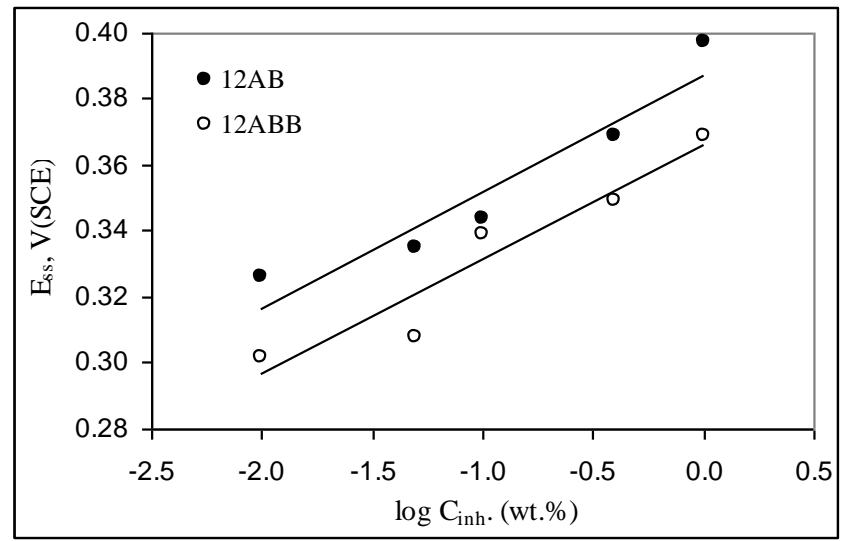

Figure (4): Variation of steady state potential of Mo Electrode at $50 \mu \mathrm{Acm}^{-2}$ as a function of $\log$ [inhibitor] of additives $12 \mathrm{AB}$ and $12 \mathrm{ABB}$ soluble in $0.01 \mathrm{M} \mathrm{HCl}$

Behavior of anodic passive film of molybdenum in $0.01 \mathrm{M} \mathrm{HCl}$ containing different percentages of $12 A B$ and $12 A B B$

Anodic oxide films were formed in $0.01 \mathrm{M} \mathrm{HCl}$ solution at constant current density of $100 \mathrm{mAcm}^{-2}$ till the potential reached $0.268 \mathrm{~V}$ (the highest potential for Mo at this current density). Then the electrode was transferred to dissolving medium which was $0.01 \mathrm{M} \mathrm{HCl}$ containing different percentages of additives $12 \mathrm{AB}$ and 12ABB.

The anodic potential- time curves indicated that, the anodic oxide film was susceptible to a dissolution process. The presence of different percentages of additives $12 \mathrm{AB}$ and $12 \mathrm{ABB}$ in $0.01 \mathrm{M} \mathrm{HCl}$ shifted the stabilized potential to more 
negative values. The potentials getting more negative by increasing the concentration of both $12 \mathrm{AB}$ and $12 \mathrm{ABB}$ (Figure $5 \mathrm{a}$ and $\mathrm{b}$ ). The attainment of the steady state after dissolution of the oxide film indicated that dissolution precipitation mechanism is followed. This might be attributed to the interaction between inhibitor molecules and anodic oxide film forming an insoluble product leading to a greater area of metal being exposed to corrosive medium.
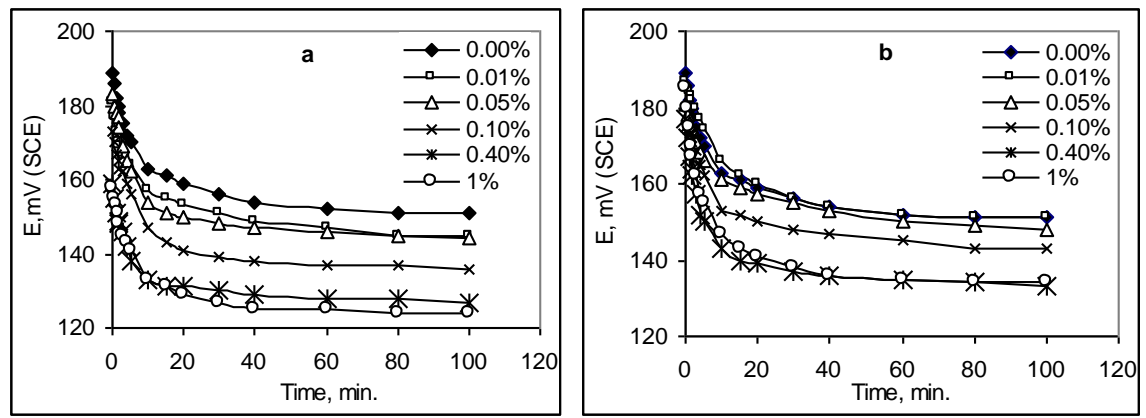

Figure (5): Potential- time curves of anodic oxide films of Mo dissolved in $0.01 \mathrm{M} \mathrm{HCl}$ containing different percentages of additives: (a) $12 \mathrm{AB}$ and (b) $12 \mathrm{ABB}$

The corrosion rates at constant current density $(\mathrm{dE} / \mathrm{dt})_{\mathrm{i}}$ were calculated from the expanded E/t relations at the first 300 second. The presence of two different corrosion rates $\left(b_{1}\right.$ for the outer layer and $b_{2}$ for the inner layer) for the dissolution process for each concentration indicated that the barrier film on Mo was duplex in nature ${ }^{(40)}$. The outer layer dissolves more quickly than the inner one (Figure 6 and Table 2).
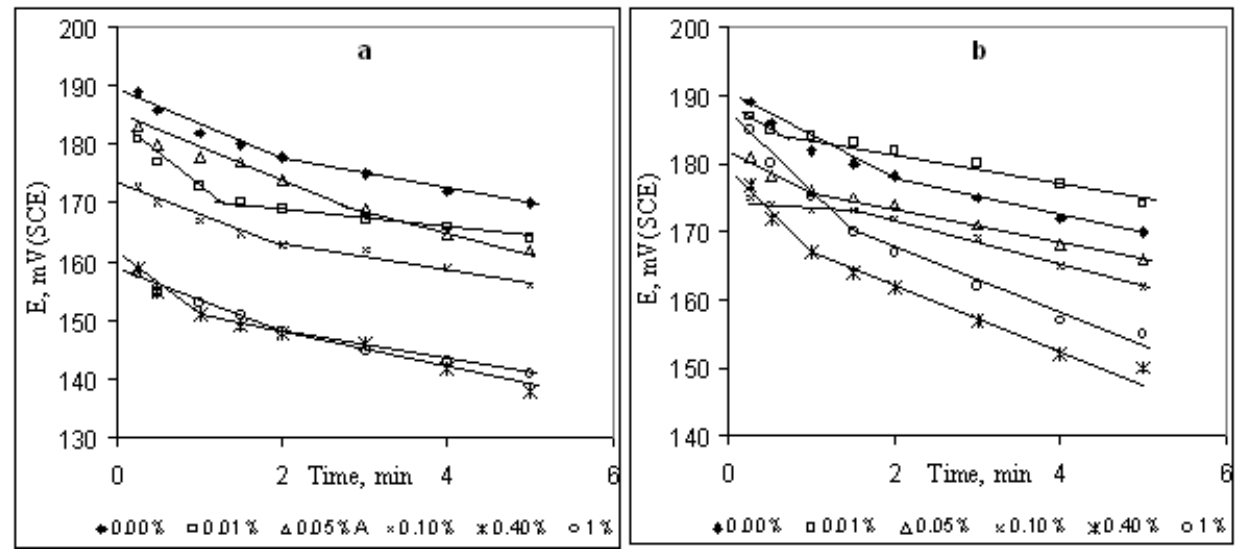

Figure (6): Anodic potential- time relations at the first 300 sec. for Mo dissolved in $0.01 \mathrm{M} \mathrm{HCl}$ containing different percentages of additives: (a) $12 \mathrm{AB}$ and (b) $12 \mathrm{ABB}$ 
Table 2: The dissolution rate coefficients, $b_{1}$ and $b_{2}$ (in $\mathrm{mV} \mathrm{min}^{-1}$ ) of anodic oxide films formed on molybdenum in $0.01 \mathrm{M} \mathrm{HCl}$ containing different weight percentages of additives $12 \mathrm{AB}$ and $12 \mathrm{ABB}$.

\begin{tabular}{|c|c|c|c|}
\hline Media & C, wt.\% & $b_{1}, m$ min $^{-1}$ & $\mathbf{b}_{2}, \mathrm{mV} \min ^{-1}$ \\
\hline Blank & 0.00 & 6.7 & 2.8 \\
\hline \multirow{5}{*}{$12 \mathrm{AB}$} & 0.01 & 12.0 & 1.5 \\
\hline & 0.05 & 4.0 & 3.6 \\
\hline & 0.10 & 5.0 & 2.0 \\
\hline & 0.40 & 11.8 & 2.9 \\
\hline & 1.00 & 5.3 & 2.0 \\
\hline \multirow{5}{*}{$12 \mathrm{ABB}$} & 0.01 & 4.4 & 2.4 \\
\hline & 0.05 & 6.0 & 2.8 \\
\hline & 0.10 & 1.6 & 3.5 \\
\hline & 0.40 & 14.0 & 4.5 \\
\hline & 1.00 & 12.0 & 3.7 \\
\hline
\end{tabular}

\section{Potentiodynamic polarization measurements:}

The increase of additive concentration lowered corrosion current densities in a little degree where the curves are greatly coincide together (Figure 7 and Table 3). This might be resulted from the increasing of surface coverage due to adsorption of the additive on the molybdenum surface as the concentration was increased. The $\mathrm{E}_{\text {corr }}$ shifted towards more noble values in the presence of additives indicating that these compounds inhibit the corrosion of $\mathrm{Mo}$ in $0.01 \mathrm{M} \mathrm{HCl}$ and affecting the anodic reaction more than cathodic one ${ }^{(41,42)}$. Furthermore, it was observed that as inhibitor concentration increased, $b_{a}$ values increased. These results revealed that these inhibitors act predominantly as anodic inhibitors. The Tafel slope variations suggested that the inhibitor influenced the mechanism of oxygen evolution reaction on the Mo electrode. The higher values of $b_{a}$ could be ascribed to the thickening of the electric double layer due to the adsorbed inhibitor molecules. These could be correlated to the decrease of the anodic transfer coefficient, which determines the Tafel slope of the $\log i_{\text {corr }}$ versus over potential curves of the oxygen evolution reaction ${ }^{(42)}$. Low IE. \% values indicated that the interaction responsible for bonding of inhibitors to a metal surface was weak and undirected interaction which might be due to electrostatic attraction between inhibiting surfactant ions and the electrically charged surface of metal ${ }^{(42)}$.

Inhibition efficiencies IE. $\%$ for different concentrations of compounds $12 \mathrm{AB}$ and $12 \mathrm{ABB}$ as a function of $\log \mathrm{C}$, increased with rising inhibitor concentration (Figure 8). Inhibition of molybdenum corrosion was attributed to the adsorption of the surfactant on the metal surface. At low concentrations, the monomers of inhibitors adsorbed at the surface individually with a low percent coverage. As the 
concentration increases, the amount adsorbed increased leading to a higher degree of coverage and consequently higher corrosion inhibition. Adsorption was enhanced in presence of $12 \mathrm{ABB}$ due to the presence of two side chain interaction. Such interaction assisted the formation of a thin film of surfactant molecules at the molybdenum surface ${ }^{(43)}$. One transition was found in the plot of IE\% versus $\log$ surfactant concentration, which was due to the transition from monolayer to multilayer of the surfactant molecules ${ }^{(44)}$.The transition point could be owing to the change from traditional submonolayer level Langmuir adsorption to multilayer $\operatorname{adsorption}^{(45)}$.
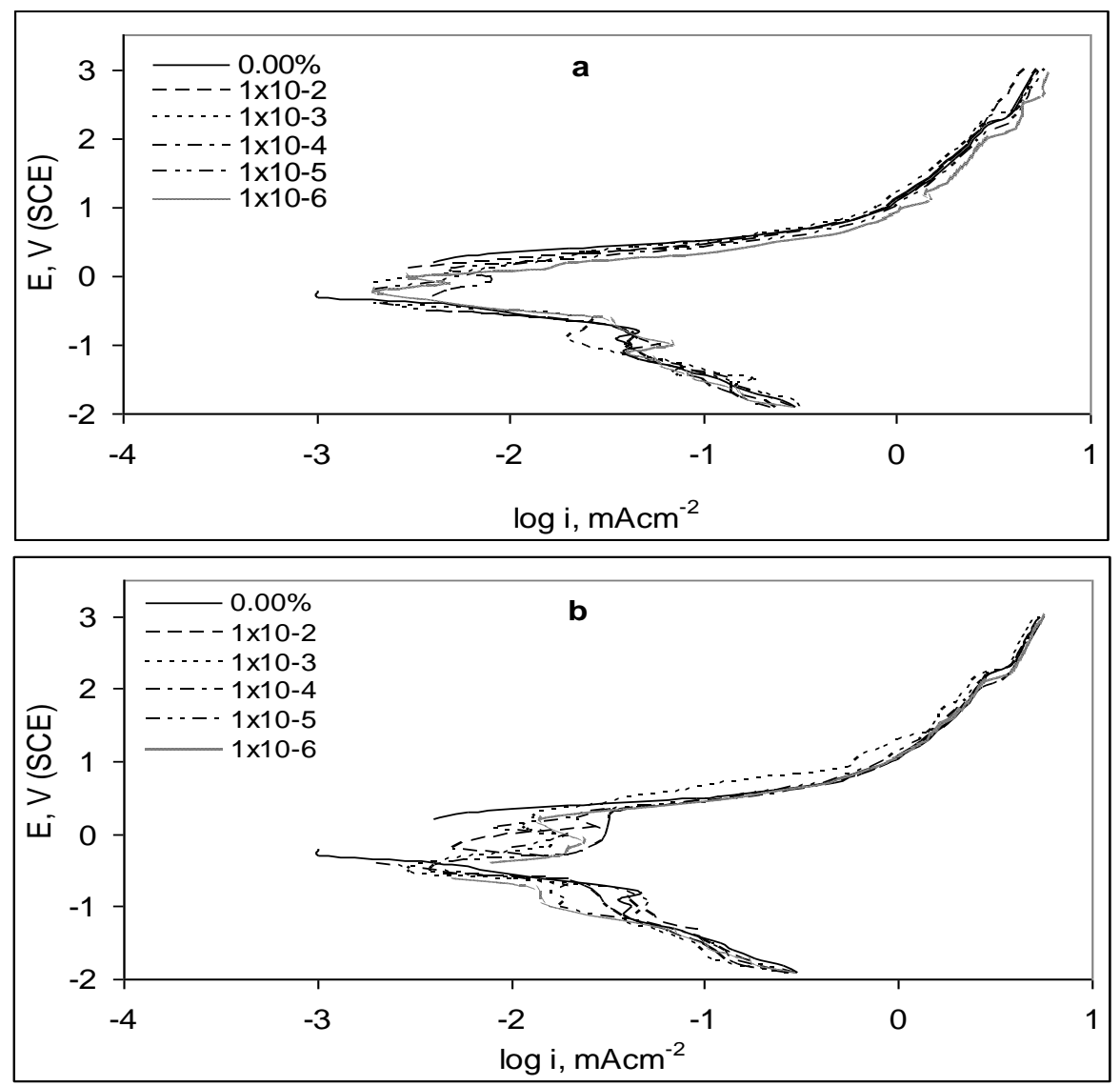

Figure (7): Potentiodynamic polarization curves of $\mathrm{Mo}$ in $0.01 \mathrm{M} \mathrm{HCl}$ containing different concentrations of additives: (a) $12 \mathrm{AB}$ and (b) $12 \mathrm{ABB}$ 
Table (3): Electrochemical parameters of Mo electrode in $0.01 \mathrm{M} \mathrm{HCl}$ containing different concentrations of additives $12 \mathrm{AB}$ and $12 \mathrm{ABB}$ at scan rate of $6.7 \mathrm{mV} / \mathrm{s}$.

\begin{tabular}{|c|c|c|c|c|c|c|}
\hline Additive & Wt.\% & $\begin{array}{c}\mathbf{E}_{\text {corr }} \\
(\mathrm{mV} / \mathrm{sce})\end{array}$ & $\begin{array}{c}\mathbf{I}_{\text {corr }} \\
\left(\mathbf{m A} / \mathbf{c m}^{2}\right)\end{array}$ & $\begin{array}{c}\mathbf{b}_{\mathbf{a}} \\
(\mathrm{mV} / \mathrm{dec} .)\end{array}$ & $\begin{array}{c}\mathrm{C}_{\mathrm{R}} \\
\mathrm{mmpy}\end{array}$ & IE. \% \\
\hline Blank & 0.00 & 700 & 0.78 & 500 & 4.85 & - \\
\hline \multirow{5}{*}{$12 \mathrm{AB}$} & $1 \times 10^{-6}$ & 705 & 0.68 & 375 & 4.22 & 13.10 \\
\hline & $1 \times 10^{-5}$ & 710 & 0.67 & 378 & 4.17 & 14.10 \\
\hline & $1 \times 10^{-4}$ & 725 & 0.65 & 583 & 4.04 & 16.66 \\
\hline & $1 \times 10^{-3}$ & 750 & 0.63 & 625 & 3.92 & 19.23 \\
\hline & $1 \times 10^{-2}$ & 715 & 0.61 & 800 & 3.79 & 21.79 \\
\hline \multirow{5}{*}{$12 \mathrm{ABB}$} & $1 \times 10^{-6}$ & 800 & 0.64 & 444 & 3.98 & 17.85 \\
\hline & $1 \times 10^{-5}$ & 760 & 0.63 & 556 & 3.92 & 19.23 \\
\hline & $1 \times 10^{-4}$ & 710 & 0.62 & 571 & 3.86 & 20.51 \\
\hline & $1 \times 10^{-3}$ & 940 & 0.60 & 667 & 3.73 & 23.07 \\
\hline & $1 \times 10^{-2}$ & 700 & 0.58 & 731 & 3.61 & 25.64 \\
\hline
\end{tabular}

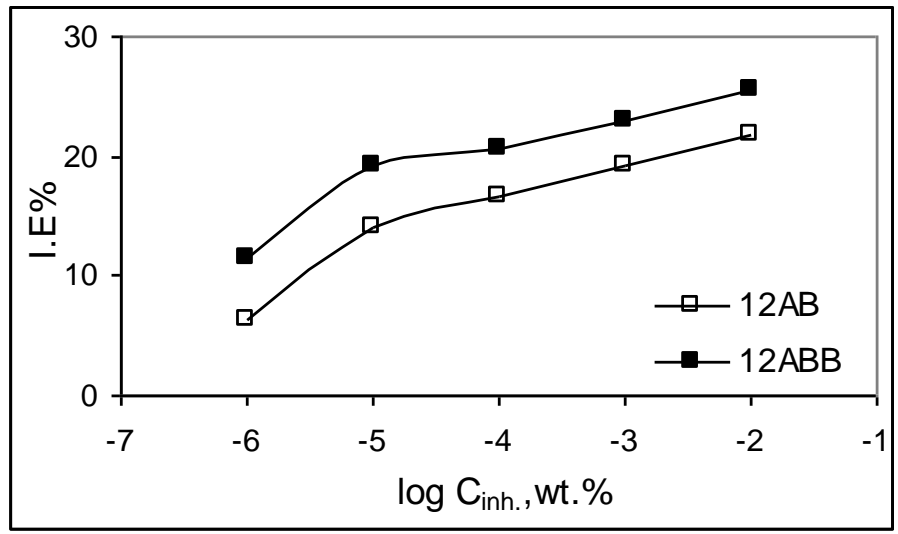

Figure (8): The relationship between inhibition efficiency (IE. \%) and $\log \left[\mathrm{C}_{\text {inh. }}\right]$

The surface coverage values $(\theta)$ were tested graphically for fitting a suitable adsorption isotherm $^{(7)}$ :

$$
\log \theta / 1-\theta=\log b+\log C_{\text {inh }}
$$

Where $b$ designates the adsorption coefficient. In these cases, the plots of $\log \theta / 1-\theta$ versus $\log C_{\text {inh }}$ yield a straight line, clearly proving that the adsorption of the used inhibitors on the molybdenum surface obeys the Langmuir isotherm (Figure 9). 
Attempts were made to fit $\theta$ values to kinetic thermodynamic model (Eq. a) ${ }^{(46)}$ and Flory-Huggins adsorption isotherm (Eq. b) ${ }^{(47)}$ :

$\log (\theta / 1-\theta)=\log (\grave{\mathrm{k}})+\mathrm{y} \log (C)$

$\log (\theta / C)=\log (\mathrm{xk})+\mathrm{X} \log (1-\theta)$

where $(\theta)$, is a degree of coverage, $y$, is the number of inhibitor molecules occupying one active site, $\mathrm{X}$, is the number of adsorbed water molecules replaced by one molecule of surfactant inhibitor, $\mathrm{K}$, is the equilibrium constant of the adsorption reaction, $C$, is the inhibitor concentration in the bulk of solution. A plot of $\log (\theta / 1$ $\theta)$ against $\log C$ and $\log (\theta / C)$ against $\log (1-\theta)$ for different concentrations showed a straight lines indicating that adsorption followed the kinetic thermodynamic model and Flory-Huggins adsorption isotherm, respectively.

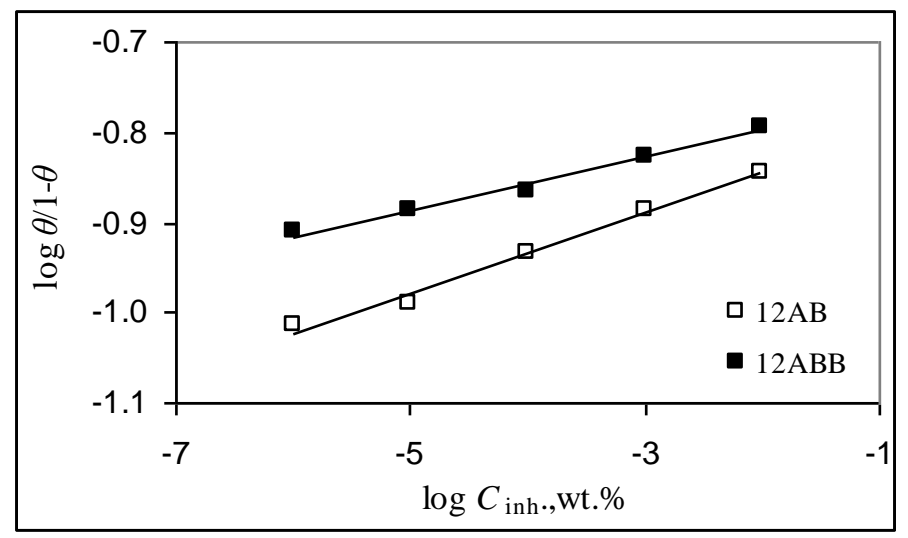

Figure (9): Langmuir isotherm for adsorption of used inhibitors on the surface of Mo electrode

\section{Potentiostatic polarization measurement:}

As the applied potentials were increased, the instantaneous current densities were also increased. For higher applied potentials (400 to $900 \mathrm{mV} / \mathrm{SCE}$ ), sharp increases in the current was observed within the first 15 second. $3 \mathrm{mAcm}^{-2}$ at applied potential of $400 \mathrm{mV}(\mathrm{SCE}), 2 \mathrm{mAcm}^{-2}$ for 500 and $600 \mathrm{mV}(\mathrm{SCE})$ and $4 \mathrm{mAcm}^{-2}$ for 900 $\mathrm{mV}$ (SCE) from the instantaneous current densities. At $300 \mathrm{mV}$ (SCE), the current density increased smoothly before stability. While at 100 and $200 \mathrm{mV}(\mathrm{SCE})$, the current showed no change with time and remaind constant (Figure 10). This could be illustrated by the fact that, as the applied potential increased, the rate of chemical attack of the oxide film increased ${ }^{(36,48)}$. Besides, the rate of anion penetration became pronounced. 
The apparent valency of the Mo passing into solution was approximately 6, but lowered as the solution became acidic. The Mo surface became covered with $\mathrm{Mo}_{2} \mathrm{O}_{5}$ oxide. The anodic dissolution, as illustrated by the increase in current density with applied potential, was controlled by the rate of oxidation of this oxide to $\mathrm{MoO}_{3}$. The resistance of corrosion was ascribed to the $\mathrm{Mo}_{2} \mathrm{O}_{5}$ film ${ }^{(35,49)}$.

$$
2 \mathrm{MoO}_{3}+2 \mathrm{H}^{+}+2 \mathrm{e}^{-} \longrightarrow \mathrm{Mo}_{2} \mathrm{O}_{5}+\mathrm{H}_{2} \mathrm{O}
$$

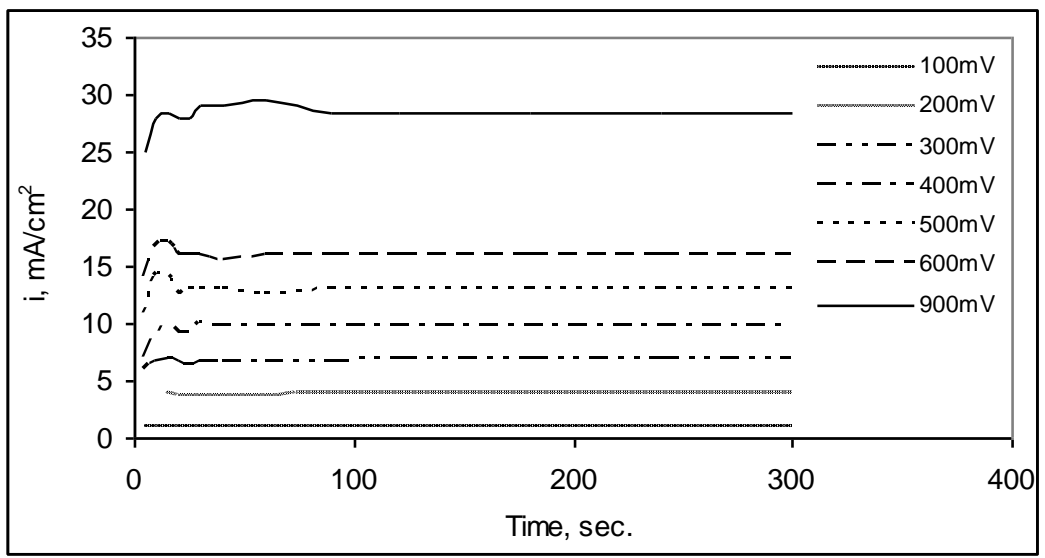

Figure (10): Potentiostatic polarization curves for Mo electrode in $0.01 \mathrm{M} \mathrm{HCl}$ at various applied potentials

The behavior of Mo in presence of $0.1 \%$ compounds $12 \mathrm{AB}$ and $12 \mathrm{ABB}$ soluble in $0.01 \mathrm{M} \mathrm{HCl}$ is similar to that without additives (Figure $11 \mathrm{a}$ and $\mathrm{b}$ ). The present results demonstrated that, in potentiostatic measurements, when the applied potential increased, the quantity of the anodic surface charging capacity of the anodic layer increases. As a consequence, the number of Mo compounds in higher oxidation states exceeded the number of Mo compounds in lower oxidation states. Similar behavior in titanium metal was previously reported ${ }^{(50)}$. Values of stabilized current density and surface charging capacity for Mo in $0.01 \mathrm{M} \mathrm{HCl}$ was always $\geq$ the values in presence of $12 \mathrm{AB}$ and $12 \mathrm{ABB}$ in all applied potentials (Table 4). This illustrated the action of additives on the corrosion inhibition of molybdenum in $0.01 \mathrm{M} \mathrm{HCl}$. Moreover, values of $i_{s}$ and $C$ for Mo in presence of $12 \mathrm{AB}$ was higher than those of $12 \mathrm{ABB}$. This facilitated the better action of $12 \mathrm{ABB}$ as a result of the presence of two side chains in its structure. These results were in good agreement with those obtained in potentiodynamic polarization measurements. 

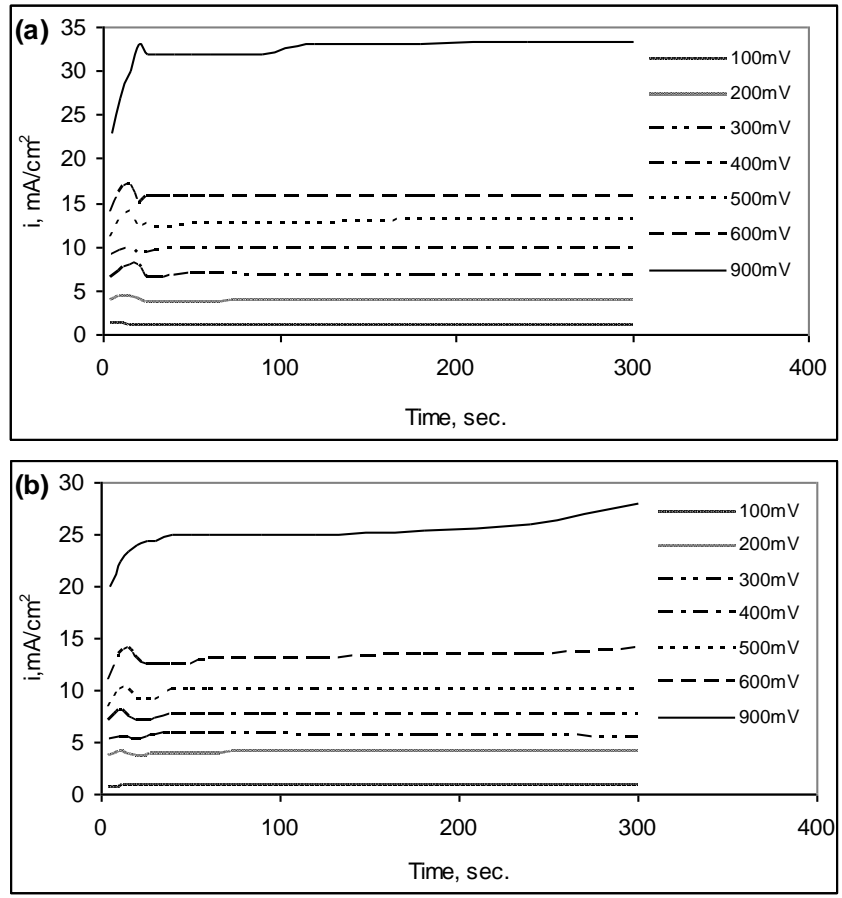

Figure (11): Potentiostatic polarization curves for Mo in 0.01 $\mathrm{M} \mathrm{HCl}$ containing $0.1 \%$ of additives at various potentials: (a) $12 \mathrm{AB}$ and (b) 12ABB

Table (4): Values of $i_{s}$, and $\mathrm{C}$ for Mo in $0.01 \mathrm{M} \mathrm{HCl}$ without and with $0.1 \%$ of $12 \mathrm{AB}$ and $12 \mathrm{ABB}$ at different applied potentials.

\begin{tabular}{|c|c|c|c|c|c|c|}
\hline \multirow{2}{*}{$\begin{array}{c}\text { Applied } \\
\text { Potential, } \\
\text { mV }\end{array}$} & \multicolumn{2}{|c|}{ 0.01MHCI } & \multicolumn{2}{|c|}{$\begin{array}{l}0.1 \% 12 \mathrm{AB} \\
\text { in } 0.01 \mathrm{M} \mathrm{HCl}\end{array}$} & \multicolumn{2}{|c|}{$\begin{array}{l}0.1 \% \text { 12ABB } \\
\text { in } 0.01 \mathrm{M} \mathrm{HCl}\end{array}$} \\
\hline & $\begin{array}{c}\mathbf{i}_{\mathrm{s}}, \\
\mathrm{mAcm}^{-2}\end{array}$ & $\mathrm{C}, \mathrm{mF} / \mathrm{cm}^{2}$ & $\begin{array}{c}\mathbf{i}_{s}, \\
\mathrm{mAcm}^{-2}\end{array}$ & $\mathrm{C}, \mathrm{mF} / \mathrm{cm}^{2}$ & $\begin{array}{c}\mathbf{i}_{\mathrm{s}}, \\
\mathrm{mAcm}^{-2}\end{array}$ & $\mathrm{C}, \mathrm{mF} / \mathrm{cm}^{2}$ \\
\hline 100 & 1.2 & 0.18 & 1.2 & 0.14 & 1.0 & 0.16 \\
\hline 200 & 4.0 & 0.32 & 4.0 & 0.30 & 3.7 & 0.17 \\
\hline 300 & 6.8 & 0.41 & 6.7 & 0.39 & 5.5 & 0.18 \\
\hline 400 & 9.8 & 0.75 & 9.6 & 0.38 & 7.6 & 0.20 \\
\hline 500 & 13.0 & 0.78 & 13.0 & 0.42 & 10.0 & 0.30 \\
\hline 600 & 16.0 & 0.80 & 15.5 & 0.43 & 14.0 & 0.35 \\
\hline 900 & 28.5 & 0.97 & 21.0 & 0.73 & - & - \\
\hline
\end{tabular}

Molybdenum placed in $0.01 \mathrm{MHCl}$ containing different concentrations of $12 \mathrm{AB}$ at constant applied potential of $200 \mathrm{mV} / \mathrm{SCE}$ suffers continuous change in current density at first 120 second (Figure 12a). This unstable behavior might be due to the anodic dissolution of a primary film (indicated by initial increasing in current 
density) which controlled by the rate of oxidation of $\mathrm{Mo}_{2} \mathrm{O}_{5}$ formed on the surface of Mo metal to $\mathrm{MoO}_{3}$. This produce a super saturated solution with respect to $\mathrm{Mo}_{2} \mathrm{O}_{5}$ and after a time this oxide is precipitated explaining the unique behavior after a certain time $\approx 180$ sec. ${ }^{(35)}$.

It was noticeable that in the presence of $12 \mathrm{ABB}$, the anodic current density was raised during the first 10 seconds indicating oxide film rupture. Then, the current density was rapidly decreased till stabilization values. In low concentrations $(0.01$ and $0.05 \%$ ), the corrosion rate was reduced due to the adsorbed action of used surfactants. However in the highest concentration $(0.4 \%)$, the current did not reach stability and was in continuous increase (Figure $12 \mathrm{~b}$ ). The adsorbed film break up and the corrosion rate increased due to the presence of decomposition products including sulphides ${ }^{(35)}$. It was found however that at $200 \mathrm{mV}$ (SCE), when the concentration of the additive $12 \mathrm{ABB}$ exceeded a critical value $(\geq 0.1 \%)$ there was no inhibition action.
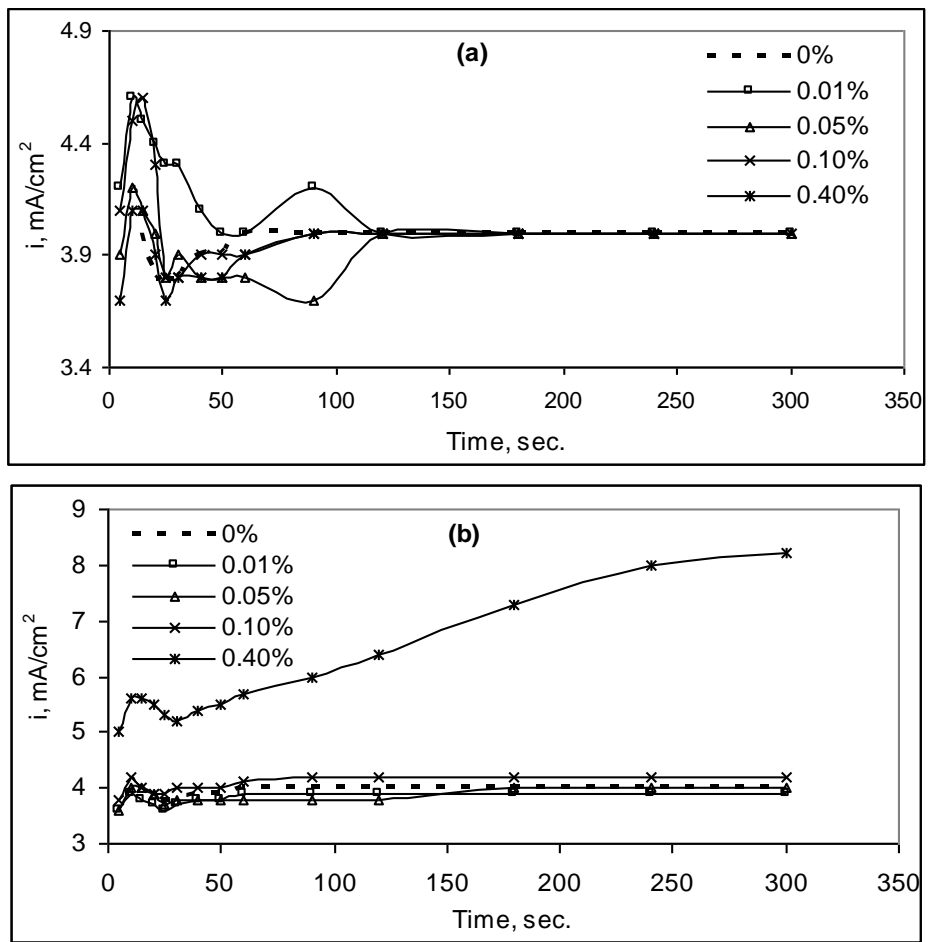

Figure (12): Potentiostatic polarization curves for Mo electrode in 0.01M $\mathrm{HCl}$ containing different $\mathrm{wt}$ \% of additives at $200 \mathrm{mV}(\mathrm{SCE})$ : (a) $12 \mathrm{AB}$ and (b) 12ABB. 


\section{Conclusion}

$12 \mathrm{AB}$ and $12 \mathrm{ABB}$ behaved as weak anodic inhibitors for molybdenum electrode. The inhibition was due to the adsorption of the surfactant on the surface of Mo electrode and blocking its active sites. The inhibition efficiency increases with the increase of inhibitor concentrations. Adsorption followed the kinetic thermodynamic model, Langmuir and Flory-Huggins adsorption isotherms.

\section{Acknowledgment}

Great gratitude to Assistant Professor Dr. F. H. Abd- El- Salam; Applied organic chemistry, Faculty of Science (Girls), Al-Azhar University, for preparation and synthesis of compounds.

\section{References}

1. J. M. Bastidas, P. Pinilla, J. L. Polo and S. Miguel; Corros. Sci. 45 (2003), pp. 427.

2. A. E. Bolzan, I. B. Wakenge, R. C. V. Piatti, R. C. Salvarezza and A. J. Arria; J. Electroanal. Chem. 501 (2001), pp. 241.

3. S. T. Keera and M. A. Deyab; Colloids Surf. A: Physicochem. Eng. Aspects 266 (2005), pp. 129.

4. M. Elachouri, M. S. Hajji, M. Salem, S. Kertit, J. Aride, R. Coudert and E. Essassi; Corros. 52 (1996), pp. 103.

5. G. N. Mu, T. P. Zhao, M. Liu and T. Gu; Corros. 52 (1996), pp. 853.

6. F. Zucchi, G. Trabanelli and G. Brunoro; Corros. Sci. 33 (1992), pp. 1135.

7. A. Tizpar and Z. Ghasemi; Appl. Surf. Sci. 15 (2006), pp. 8630.

8. E. Stipnisek-Lisac, A. Gazivoda and M. Madzarac; Electrochim. Acta 47 (2002), pp. 4189.

9. M. Sahin, S. Bilgic and H. Yilmaz; Appl. Surf. Sci. 195 (2002), pp. 1.

10. B. Hoyer and N. Jensen; J. Electroanal. Chem. 601(2007), pp. 153.

11. B. Hoyer and N. Jensen; Electrochem. Commu., 8(2) (2006), pp. 323.

12. J. Cruz, T. Pandiyan and E. Garcia-Ochoa; J. Electroanal. Chem. 583 (2005), pp. 8.

13. A. Nosal-Wiercinska, Z. Fekner and G.Z. Dalmata; J. Electroanal. Chem. 584 (2005), pp. 192.

14. R. BuBar, M. Nielinger and H. Baltruschat; J. Electroanal. Chem. 578 (2005), pp. 259.

15. J. G. N. Thomas, in: Proceedings of the Fifth European Symposium on Corrosion Inhibitors, Ann. Univ., Ferrara, Italy (1981), pp. 453. 
16. M. M. Saleh and A. A. Atia; J. Appl. Electrochem. 36 (2006), pp. 899.

17. L. Niu, H. Zhang and F. Wei; Appl. Surf. Sci. 252 (2005), pp. 1634.

18. S. Mohanan, S. Maruthamuthu and N. Kalaiselvi; Corros. 23 (2005), pp. 425.

19. H. Akatsuka, Y. Ohara and Y. Otsubo; J. Collo. and Interf. Sci., 302 (2006), pp. 341.

20. L. Huang, C. Maltesh and P. Somasundaran; J. Collo. and Interf. Sci., 177 (1996), pp. 222.

21. J. Savkovic-Stevanovic, T. Mošorinac, B. R. Snežana and D. B. Ružica; Computer Aided Chemical Engineering, 24 (2007), pp.195.

22. L-G. Qiu, A-J. Xie, Y-H. Shen ; Mater.Chem. and Phy., 91(2005), pp. 269.

23. G. Lissens, J. Pieters, M. Verhaege, L. Pinoy and W. Verstraete; Electrochim. Acta, 48(2003), pp.1655.

24. Y. Kuwahara, A. Goto, Y. Ibuki, K. Yamazaki and R. Goto; J. Collo. and interf. Sci., 233 (2001), pp. 190.

25. P. Tang, X. Jia, D. Fan, L. Wang, J. Hao; Colloids Surf. A: Physicochem. Eng. Aspects 312 (2008), pp. 18.

26. B. Wicek and U. Twardoch; J. Phys. and Chem. of Solids, 65 (2004), pp. 263.

27. M. Bojinov, I. Betova and R. Raicheff; J. Electroanal. Chem., 411 (1996), pp. 37.

28. W. A. Badawy, A. G. Gad-Allah, H. A. Abd El-Rahman and M. M. Abouromia; Surf. and Coat. Techn., 30 (1987), pp. 365.

29. W. A. Badawy, A. G. Gad-Allah, H. A. Abd El-Rahman and M. M. Abouromia; Surf. and Coat. Techn., 27 (1986), pp. 187.

30. N. M. Hull; J. Electroanal. Chem., 38 (1972), pp. 143.

31. M. Bojinov, I. Betova and R. Raicheff; J. Electroanal. Chem., 381 (1995), pp. 123.

32. M. Bojinov, I. Betova and R. Raicheff; Electrochim. Acta, 41, (1996), pp. 1173.

33. J. E. Johnson, C. H. Chi, C. K. Chen and W. J. James; Corros. 36 (1970), pp. 238.

34. I. L. Rozendeld; Corrosion Inhibitors, McGraw-Hill, New York, NY (1981) p. 327.

35. U. R. Evans; The corrosion and oxidation of metals 2nd supplementary volume (1976), pp. 162.

36. A. G. Gadallah, W. A. Badawy, H. H. Rehan; J. Appl. Elechtrochem. 19 (1989), pp.768.

37. L. Young; Anodic oxide films. Academic Press, London 1961.

38. J. M. Albella, I. M. Montero and J. I. Martinz- Duart; Thin solid films, 125 (1985), pp. 57.

39. E. M. Attia; Al - Azhar Bull. Sci. 17 (2006), pp. 53. 
40. E. M. Attia, A. E. EL- Shennawy and W. A. M. Hussein; Al - Azhar Bull. Sci. 19 (2008), pp. 27.

41. S. Sayed . Abd El Rehim, H. H. Hassan, M. A. Amin; Mater. Chem. and Phys. 70 (2001), pp. 64.

42. G. Quartarone, L. Bonaldo and C. Tortato; Appl. Surf. Sci. 252 (2006), pp. 8251.

43. M. A. Deyab; Corros. Sci. 49 (2007), pp. 2315.

44. M. L. Free; Corros. Sci. 44 (2002), pp. 2865.

45. L-G. Qiu, Y. Wu, Y-M. Wang, X. Jiang ; Corros. Sci. 50 (2008), pp. 576.

46. A. A. El-Awady, B. A. El Naby and S. G. Aziz; J. Electrochem. Soc. 139 (1992), pp. 2149 .

47. H. Dhar, B. Conway and K. Joshi; Electrochim. Acta 18 (1973), pp. 789.

48. M. S. El- Basiouny, A. M. Bekheet and A. G. gad Allah; Corros. 41 (1984), pp. 116.

49. W. A. Badawy and F. M. Al- Khrafi; Electrochem. Acta 44 (1998), pp. 693.

50. A. S. I. Ahmed, K. J. Friesen and A. S. Abd El- Aziz; J. Sci. and Techn. 12 (2000), pp. 5. 